\title{
MEASURING THE TOURIST SATISFACTION ON ECOTOURISM SERVICE QUALITY AT KUALA TAHAN NATIONAL PARK: AN INVESTIGATION ON VISITORS PERCEPTIONS
}

\author{
Aleff Omar Shah Nordin ${ }^{1}$, Mohd Rahimi Abdul Halim² \& Siti Nur Atiqah Mohd Masri ${ }^{3}$ \\ 1,2,3Faculty of Business, Economics, and Social Development, Universiti Malaysia Terengganu \\ (aleff.shah@umt.edu.my,m.rahimi@umt.edu.my, cikatiqahmasri1409@gmail.com)
}

\begin{abstract}
Ecotourism is a sub-component of sustainable tourism that involves a visit to a natural area and manages the living parts of the natural environment. Moreover, ecotourism's perceived potential as an effective tool for sustainable development, including economic development and conservation strategies. Currently, the importance of ecotourism service quality is gaining tremendous attention due to the growing demand for ecotourism worldwide and increasing expectations from visitors. A challenge remains in identifying how natural resource and nature-based tourism providers can best achieve those benefits and increase the visitor's satisfaction levels, while at the same time minimising the effects of degradation to the natural resource being used. Hence, the main purpose of this study is to assess the ecotourism services quality at Kuala Tahan National Park. This study will adopt the ECOSERV instrument to measure visitor's expectations and perceptions of service quality. This study was conducted using a quantitative approach by obtaining responses from 153 tourists. Based on service quality provided at Kuala Tahan National Park, visitor's were satisfied with the services provided there. The data collected was analysed using descriptive statistics and Multiple Regression Analysis to achieve the objectives of the study. This study also finds the responsiveness, empathy, and assurance have a significant relationship with service quality at Kuala Tahan National Park. However, they have an unsignificant relation between ecotangibles, tangible and reliability with tourist's satisfaction. The finding of this study is important for ecotourism activity at Kuala Tahan National Park and for government be able to promote ecotourism product as the main attraction in Malaysia.
\end{abstract}

KEYWORDS: Ecotourism, ECOSERV, tourist satisfaction, service quality, Kuala Tahan National Park

\section{PURPOSE AND BACKGROUND}

Tourism has been recognised as one of the largest industries and a major socio-economic activity in the world. It has been acknowledged as a tool for bringing economic benefits to a country or a specific region (Kisi, 2019). Tourism was defined as a collection of activities, services and industries which is deliver a travel experience comprising transportation, accommodation, eating and drinking establishments, retails shops entertainment businesses and hospitality services is provide for individuals or group travelling away from home (Alam, Er, Begum, Alam, 2015).

However, ecotourism also is one of the crucial components of tourism industry (KC, 2017). Ecotourism is a sub-component of sustainable tourism that involves a visit to a natural area and manages the living parts of the natural environment. Moreover, ecotourism's perceived potential as an effective tool for sustainable development, including economic development and conservation strategies.

Currently, the importance of ecotourism service quality is gaining tremendous attention due to the growing demand for ecotourism worldwide and increasing expectations from visitors. A challenge remains 
in identifying how natural resource and nature-based tourism providers can best achieve those benefits and increase the visitor's satisfaction levels, while at the same time minimising the effects of degradation to the natural resource being used. Hence, the main purpose of this study is to assess the ecotourism services quality at Kuala Tahan National Park.

\section{METHODOLOGY}

This study will adopt ECOSERV instrument to measure visitor's expectations and perceptions on service quality. This study was conducted using a quantitative approach by obtaining responses from 153 tourists. The data was gathered through the use of questionnaires distributed using online survey techniques.

The questionnaire consisted of 45 questions and was divided into three part which is; respondent's demographic, tourist satisfaction and overall satisfaction. Respondents were asked to indicate their level of agreement with each item in tourist satisfaction and overall satisfaction using a 5-point Likert scale. With 1 point on the Likert scale representing strongly disagree while 5 points was strongly agreed.

In this analysis of this study non-probability with a purposive sampling method has been used. The respondents were selected based on several criteria. Using the online survey as a data collection because the pandemic hinders one from conducting a face-to-face survey. Data collected was analysed using descriptive statistics and Multiple Regression Analysis to achieve the objectives of the study.

\section{FINDINGS}

Responsiveness was the highest mean of tourist's satisfaction which is 3.9853. this is because the tourists satisfied with the service that Kuala Tahan National Park provide. Tourists were satisfied with the employees at Kuala Tahan National Park because they were always willing to help them. Empathy had the lowest mean with tourists with a value of 3.8399. This is because Kuala Tahan National Park cannot fulfill their needs. The tourists have a high expectation when they come visit to one place. But when they reach the places, what the tourists expect does not match the place. That's why empathy has the lowest mean for tourist's satisfaction.

The results indicated that only three out of six variables were statistically significant $(p<0.05)$ except ecotangibles, tangibles and reliability. The result of t-test analysis found that for responsiveness $(2.352>1.9763$, sig $0.02<0.05)$, empathy $(4.986>1.9763$, sig $0.000<0.05)$ and assurance $(2.878>1.9763$, sig $0.005<0.05)$. This indicated that this variable has a significant relationship with tourist satisfaction.

The results also showed that empathy was the largest portion of the variance in tourist satisfaction. While for the variable which is ecotangibles $(3.146>1.9763$, sig $0.513>0.05)$, tangibles $(0.011<1.9763$, sig $0.991>0.05)$ and reliability $(-0.046<1.9763,0.86>0.05)$. The value for the items of the score was smaller than the t-value, indicating no significant relationship. In the other word, ecotangibles, tangibles and reliability are not determining factors for tourist satisfaction.

\section{CONCLUSION}

The objective of this study is to examine the tourist's satisfaction about ecotourism service quality at Kuala Tahan National Park based on visitor perception. Accordingly, this research summarizes the presentation of the issue, the developed research question and objectives and major contribution to the field. Finding from the study concluded that only six of the independent variables of this research, which is ecotangibles, tangible, responsiveness, reliability, empathy, and assurance are significant. 
From these findings multiple regressions of six factors were identified that responsiveness has the great influence in tourist's satisfaction compared with empathy and assurance. While the tangible, ecotangibles and reliability was the factor that does not support the tourist's satisfaction. This study also finds the responsiveness, empathy, and assurance have a significant relationship with service quality at Kuala Tahan National Park.

However there have an insignificant relation between ecotangibles, tangible and reliability with tourist's satisfaction. Recommendation that Kuala Tahan National Park should take a note to repair the damage to facilities. So, that tourists can use them without any issues. Only then will the tourist's satisfaction level increase because they are satisfied with the service provided there. The management must also make sure that equipment or facilities are safe to use. Last, to avoid the small injury becoming a serious injury, they should prepare an emergency kit or first-aid kit so that they can treat tourists if needed.

\section{CONTRIBUTION/PRACTICAL IMPLICATIONS}

The finding of this study is important for the operators, tourists, and local community to promote the national park as the ecotourism around the world is gaining momentum. This study only focuses on the service quality at Kuala Tahan National Park and tourist's satisfaction levels.

Further study is needed to know who the stakeholders are in a bid to upgrade and rebrand the national park as an ecotourism destination. The outcomes from this research will help to overcome the issue related to tourist satisfaction specifically in Kuala Tahan National Park. Finally, this research will help park management meet the expectations of tourist during their visit.

\section{REFERENCES}

Ramyar, M. \& Halim, N. (2020). Tourists expectation and satisfaction towards existing infrastructure and facilities in Golestan National Park, Iran. American Research Journal of Humanities \& Social Science (ARJHSS), 89-108.

Said, A, Shuib, A., Ayob, N., \& Yaakub, F. (2013). An evaluation of service quality from visitors' perspectives: The case of Niah National Park in Sarawak. International Journal of Business and Society, 14(1), 61-78.

Hoang Doan Phuong Thao, H. D. P., Thuy, V. T. N., Dat. T. P. M. (2019). Service quality attributes in ecotourism: The incorporation of experiential aspects. International Journal of Business and Society, 20(3), 1201. 